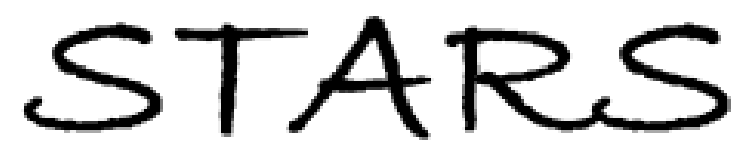

University of Central Florida

STARS

$1-1-2006$

\title{
Technique for thermal isolation of antenna-coupled infrared microbolometers
}

C. F. Middleton

University of Central Florida

G. D. Boreman

University of Central Florida

Find similar works at: https://stars.library.ucf.edu/facultybib2000

University of Central Florida Libraries http://library.ucf.edu

This Article is brought to you for free and open access by the Faculty Bibliography at STARS. It has been accepted for inclusion in Faculty Bibliography 2000 s by an authorized administrator of STARS. For more information, please contact STARS@ucf.edu.

\section{Recommended Citation}

Middleton, C. F. and Boreman, G. D., "Technique for thermal isolation of antenna-coupled infrared microbolometers" (2006). Faculty Bibliography 2000s. 6435.

https://stars.library.ucf.edu/facultybib2000/6435

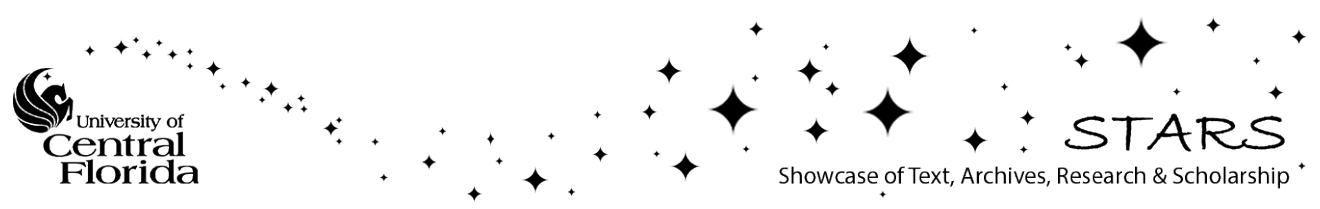




\section{Technique for thermal isolation of antenna-coupled infrared microbolometers}

C. F. Middleton, and G. D. Boreman

Citation: Journal of Vacuum Science \& Technology B: Microelectronics and Nanometer Structures Processing, Measurement, and Phenomena 24, 2356 (2006); doi: 10.1116/1.2335434

View online: https://doi.org/10.1116/1.2335434

View Table of Contents: https://avs.scitation.org/toc/jvn/24/5

Published by the American Institute of Physics

\section{ARTICLES YOU MAY BE INTERESTED IN}

Bolometers for infrared and millimeter waves

Journal of Applied Physics 76, 1 (1994); https://doi.org/10.1063/1.357128

Fabrication and design of vanadium oxide microbolometer

AIP Conference Proceedings 1809, 020001 (2017); https://doi.org/10.1063/1.4975416

Graphene bolometer with thermoelectric readout and capacitive coupling to an antenna

Applied Physics Letters 112, 063501 (2018); https://doi.org/10.1063/1.5009629

A thin film broadband absorber based on multi-sized nanoantennas

Applied Physics Letters 99, 253101 (2011); https://doi.org/10.1063/1.3672002

Metamaterial metal-based bolometers

Applied Physics Letters 100, 203508 (2012); https://doi.org/10.1063/1.4714741

Antenna-coupled infrared detectors

Journal of Applied Physics 48, 1870 (1977); https://doi.org/10.1063/1.323940 


\title{
Technique for thermal isolation of antenna-coupled infrared microbolometers*
}

\author{
C. F. Middleton ${ }^{\text {a) }}$ and G. D. Boreman \\ College of Optics and Photonics/CREOL, University of Central Florida, Orlando, Florida 32816-2700
}

(Received 15 March 2006; accepted 10 July 2006; published 25 September 2006)

\begin{abstract}
A new method was developed to thermally isolate monolithic antenna-coupled infrared microbolometers from their substrate. Using a $\mathrm{SiO}_{2}$ sacrificial layer to create a $400 \mathrm{~nm}$ thick $\mathrm{Si}_{3} \mathrm{~N}_{4}$ membrane, square spiral antennas coupled to $\mathrm{Ni}$ microbolometers were fabricated and tested. The responsivity of the thermally isolated devices is 164 times greater than a similar device that is not fabricated on a membrane. (C) 2006 American Vacuum Society. [DOI: 10.1116/1.2335434]
\end{abstract}

\section{INTRODUCTION}

Antenna-coupled microbolometers are potential solutions as elements in focal plane arrays for lightweight, low-cost sensors in infrared and millimeter wave imaging. These uncooled detectors can be designed to operate at a wide range of frequencies. The fast time constants, low power requirements, and robustness of these monolithic devices make them an important area of research in infrared and millimeter wave imaging.

A bolometer is a material in which a change in temperature is accompanied by a corresponding change in electrical resistance. By passing a bias current through the material, one can measure temperature change by observing a change in bias voltage. The voltage responsivity $\mathfrak{R}_{v}$ of a bolometer depends on several parameters,

$$
\Re_{v}=\frac{i_{\text {bias }} R \alpha \eta}{G \sqrt{1+\omega^{2} \tau^{2}}} .
$$

Here $i_{\text {bias }}$ is the bias current supplied to the bolometer, $R$ is the resistance of the bolometer, $\alpha$ is the material temperature coefficient of resistance (TCR), $\eta$ is an optical absorption coefficient, $G$ represents the thermal conductivity of the bolometer's primary means of heat loss, $\omega$ is the modulation frequency of the incident radiation, and $\tau$ is the thermal time constant. $^{1}$

Because responsivity is directly proportional to TCR, the choice of bolometric material is important. But since this number varies by only a few percent in most readily available materials, the inverse proportionality of thermal conductivity $G$ has a greater effect on responsivity.

A faster thermal time constant allows the device to be used in a wider range of applications. The time constant depends on the physical size of the bolometer: a smaller bolometer has a faster time constant. But as the bolometer gets smaller, its collection area also gets smaller, making it less effective as a sensor. To increase the collection area of the bolometer without increasing its physical size, one can couple the bolometer to an antenna. If the antenna is designed to resonate at the desired frequency, radiation can be

\footnotetext{
*No proof corrections received from author prior to publication.

a)Electronic mail: cmiddlet@mail.ucf.edu
}

directed into the bolometer and responsivity will increase. The choice of antenna determines the resonant frequency, bandwidth, and polarization of the device. Ground planes and arrays of antennas can also be used to increase the response of a bolometer.

Antenna-coupled microbolometers are generally monolithic structures that can be fabricated using standard integrated circuit manufacturing techniques, such as optical lithography and thin film deposition. The devices are operated at room temperature and have low power requirements.

Our present antenna design is a square spiral, which has a large bandwidth and approximately circular polarization dependence. $^{2}$ The antenna structure is written using electron beam lithography, with minimum feature size of $450 \mathrm{~nm}$. To increase the thermal isolation of the bolometer, we fabricate the devices on silicon nitride membranes and measure their response under vacuum.

The antenna metal was chosen based on the ellipsometric characterization of metals in the infrared. A variable-angle spectroscopic ellipsometer was used to measure the optical constants of four metals: $\mathrm{Al}, \mathrm{Au}, \mathrm{Ni}$, and Ti. From these measurements we calculated the electrical conductivity of the metals,

$$
\sigma(\lambda)=\frac{4 \pi c n k \varepsilon_{0}}{\lambda}
$$

where $n$ and $k$ are the real and imaginary parts of the refractive index, $\varepsilon_{0}$ is the permittivity of free space, $c$ is the speed of light, and $\lambda$ is the wavelength. ${ }^{3}$ Figure 1 shows the conductivity of these metals over the wavelength range of $8-12 \mu \mathrm{m}$. Nickel was selected as the antenna/bolometer metal based on its high electrical conductivity (higher than $\mathrm{Au}$ or $\mathrm{Ti}$ ), low thermal conductivity (lower than $\mathrm{Al}$ or $\mathrm{Au}$ ), and high temperature coefficient of resistance (higher than $\mathrm{Al}, \mathrm{Au}$, or $\mathrm{Ti})$.

\section{FABRICATION}

The antenna-coupled devices were fabricated on a $400 \mathrm{~nm}$ low pressure chemical vapor deposited (LPCVD) $\mathrm{Si}_{3} \mathrm{~N}_{4}$ layer, which was deposited on a $3 \mu \mathrm{m}$ thermally grown $\mathrm{SiO}_{2}$ layer on a $\mathrm{Si}$ substrate. Square spiral antennas were written in positive-tone electron-beam resist bilayer [polydimethyl- 


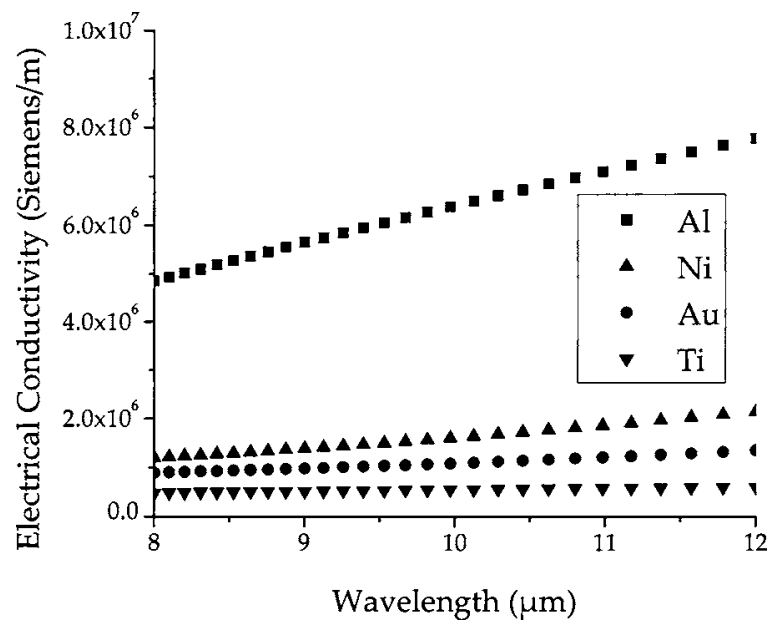

FIG. 1. Frequency dependence of the electrical conductivity of $\mathrm{Al}, \mathrm{Au}, \mathrm{Ni}$, and $\mathrm{Ti}$, based on ellipsometric measurements from 8 to $12 \mu \mathrm{m}$.

glutarimide (PMGI) SF-7 on ZEP 520A-7] with our Leica EBPG 5000+. The use of PMGI as a lift-off resist layer underneath the ZEP imaging resist layer allows control of undercut dimensions. Both resist layers were spun onto the substrate at $3000 \mathrm{rpm}$ for $80 \mathrm{~s}$, corresponding to thickness of $450 \mathrm{~nm}$ for PMGI and $300 \mathrm{~nm}$ for ZEP. Each layer was baked on a hot plate at $180{ }^{\circ} \mathrm{C}$ for $3 \mathrm{~min}$ (PMGI) and $4 \mathrm{~min}$ (ZEP). No adhesion promoter was found to be necessary for this process.

We exposed the resist bilayer with a dose of $120 \mu \mathrm{C} / \mathrm{cm}^{2}$, with the $e$ beam operating at $50 \mathrm{kV}$. The ZEP layer was then developed for $90 \mathrm{~s}$ in xylene, and the PMGI layer was developed for $20 \mathrm{~s}$ in tetramethyl ammonium hydroxide (TMAH) developer (2.3\%). The PMGI developer was perhaps too aggressive and could be diluted to give longer, more repeatable development times, but we had adequate device uniformity with this method. It was not necessary to descum the wafer before metal deposition.

$\mathrm{Ni}$ was deposited in a thickness of $150 \mathrm{~nm}$, via dc magnetron sputtering onto the substrate. To lift off the metal and remove the resist bilayer, we placed the wafer first in methylene chloride for $30 \mathrm{~min}$. This removed the layer of ZEP resist, as well as any $\mathrm{Ni}$ on top of the resist layer. Then we placed the wafer for $30 \mathrm{~min}$ in EBR-PG, the edge-bead remover sold by MicroChem, which consists mainly of 1,3 dioxolane and propylene glycol monomethyl ether. This removed the PMGI resist layer, leaving only the Ni antennacoupled microbolometers.

Membranes were created underneath the antenna-coupled devices by coating the wafer with positive-tone photoresist (Shipley S1818) and exposing two rectangles on either side of the antenna. Figure 2 shows a schematic drawing of the devices and membranes. Exposure was accomplished with a Karl Suss MJB3 contact aligner. With the photoresist as a mask, the $\mathrm{Si}_{3} \mathrm{~N}_{4}$ was reactive ion etched (RIE) in $\mathrm{CHF}_{3}$ plasma. This etch was performed with $50 \mathrm{mTorr}^{\mathrm{CHF}_{3}}$ at $1000 \mathrm{~W}$ rf power for $2 \mathrm{~min}$. Slight overetching into the $\mathrm{SiO}_{2}$ layer occurred, but this only helped with the next step.
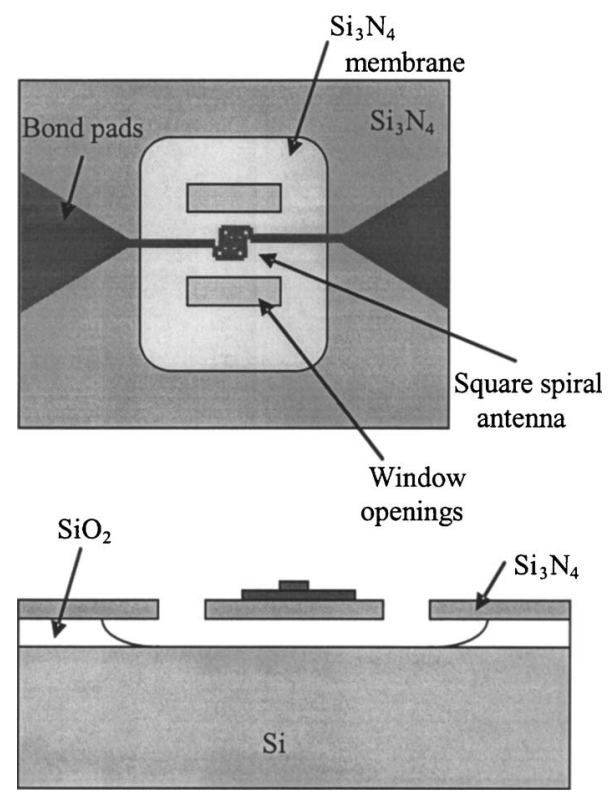

FIG. 2. Top view and cross section of antenna-coupled microbolometer on $\mathrm{Si}_{3} \mathrm{~N}_{4}$ membrane.

A mixture of nine parts ammonium fluoride to one part hydrofluoric acid, known as buffered oxide etch (BOE), was then used to etch the $\mathrm{SiO}_{2}$ underneath the $\mathrm{Si}_{3} \mathrm{~N}_{4}$. The photoresist provided a sufficient mask for the antenna metal, which would otherwise have been removed by the etchant during the $3 \mathrm{~h}$ etch. The isotropic nature of wet etching caused the $\mathrm{SiO}_{2}$ directly beneath the antenna-coupled devices to be removed, leaving the devices suspended on the $400 \mathrm{~nm}$ layer of $\mathrm{Si}_{3} \mathrm{~N}_{4}$. In the final step, acetone was used to remove the photoresist mask. This nitride layer was robust enough that critical point drying was not necessary in releasing the devices, due in part to the thickness of the nitride and also to the deposition method: LPCVD yields a lower-stress film than plasma-enhanced chemical vapor deposition (PECVD). Images of the devices are shown in Fig. 3.

Initial attempts at membrane fabrication relied on $e$-beam resist for the RIE mask to etch $\mathrm{Si}_{3} \mathrm{~N}_{4}$ and used no mask during the $\mathrm{BOE}$ etch. For this reason, $\mathrm{Au}$ and $\mathrm{Cr}$ were the only possible metal choices, as they are not removed by hydrofluoric acid. ${ }^{4}$ We desired to develop a fabrication process that would allow the use of arbitrary antenna and bolometer materials, so we first tried to create the membranes by coating the antenna-coupled microbolometers with several hundred nanometers of thermally evaporated $\mathrm{Cr}$, then masking the $\mathrm{Cr}$ with photoresist, wet etching windows in the $\mathrm{Cr}$, RIEing those same windows in the $\mathrm{Si}_{3} \mathrm{~N}_{4}$, wet etching the $\mathrm{SiO}_{2}$ in $49 \% \mathrm{HF}$, and finally etching away the remaining Cr. This process failed because the $\mathrm{Cr}$ was not an adequate mask for $\mathrm{HF}$, and the $\mathrm{Cr}$ etchant also etched several candidate antenna metals, such as Ti. Our present approach, using photoresist as a mask instead of $\mathrm{Cr}$ and using BOE instead of straight $\mathrm{HF}$, is a much simpler and more effective process. Bolometric materials that would normally be removed by HF can now be included in the process. The choice of $\mathrm{Ni}$ in this 

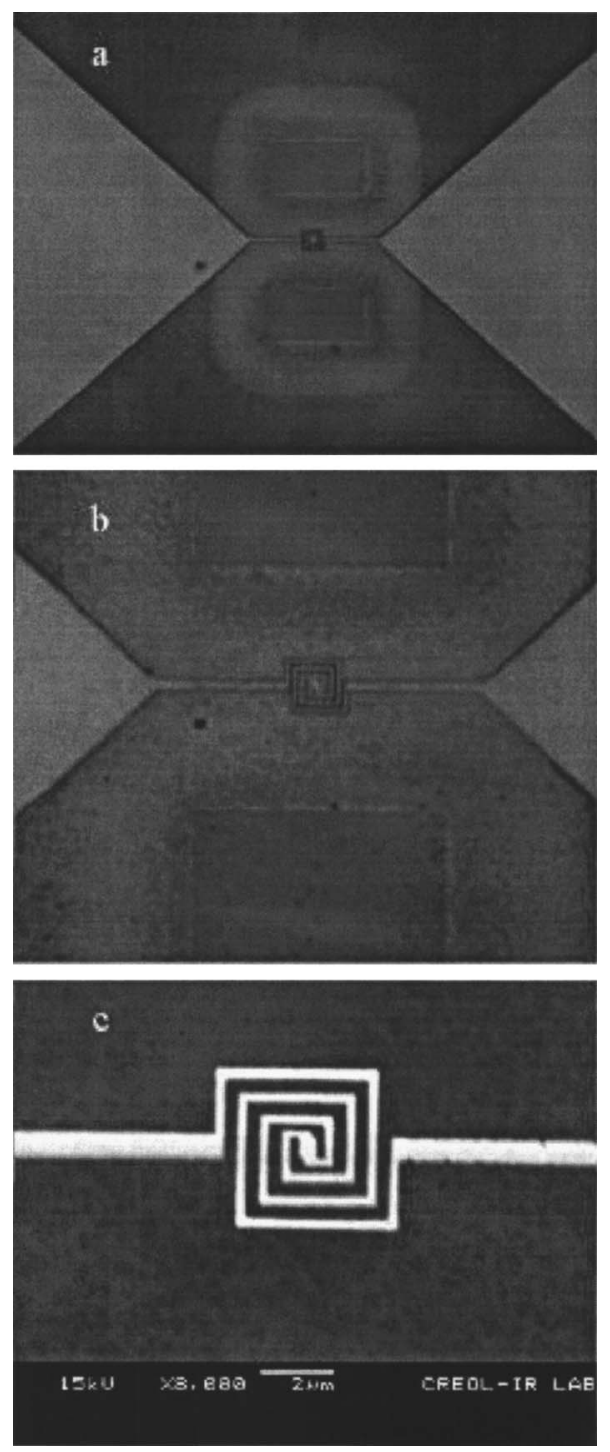

FIG. 3. Optical and scanning electron microscope images of antennacoupled microbolometer on $\mathrm{Si}_{3} \mathrm{~N}_{4}$ membrane.

work is due largely to the ease of deposition and Ni's slightly higher TCR ( $\sim 0.6 \%$, compared to $0.4 \%$ in most metals).

\section{MEASUREMENTS AND CHARACTERIZATION}

Infrared measurements of the devices were carried out with the test setup shown in Fig. 4. The source, a tunable $\mathrm{CO}_{2}$ laser (9-11 $\mu \mathrm{m}$ wavelength), passes through a neutral density filter (NDF) and a wire grid polarizer, which attenu-

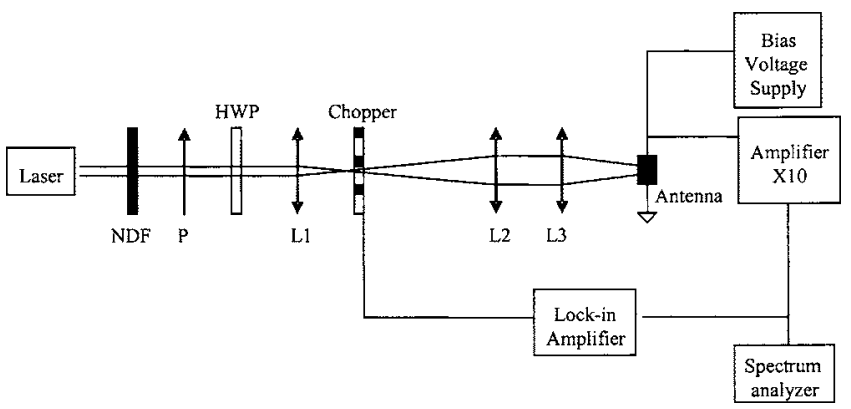

FIG. 4. Test setup for IR antenna-coupled microbolometer measurement.

ate the power incident on the detector. A half wave plate (HWP) allows control of the incident polarization of the beam. Several lenses are used to focus the beam, first through a mechanical chopper which modulates the laser beam at $2.5 \mathrm{kHz}$, and then to an $F / 8$ focus, which has a spot size of $250 \mu \mathrm{m}$.

The device was mounted in an evacuated Dewar with a $\mathrm{ZnSe}$ window, on a three-axis micropositioner stage. A roughing pump was used to evacuate the Dewar to a pressure of 20 mTorr. A bias voltage of $150 \mathrm{mV}$ was applied, and the signal was read on a spectrum analyzer and lock-in amplifier after passing through a $10 \times$ amplifier. Using the $10.6 \mu \mathrm{m}$ $\mathrm{CO}_{2}$ laser line and illuminating the devices from the air side, we measured the response and noise figure of three types of device: Ni square spiral antenna coupled to a Ni bolometer on a substrate of $\mathrm{Si}_{3} \mathrm{~N}_{4}$ (no membrane); the same device on a $400 \mathrm{~nm} \mathrm{Si} \mathrm{N}_{4}$ membrane in air; and the same device on a $400 \mathrm{~nm} \mathrm{Si} \mathrm{N}_{4}$ membrane under vacuum. Measured results are summarized in Table I.

Knowing the incident power of the laser, the beam spot size, and the effective area of the detector, we can calculate voltage responsivity $\mathfrak{R}_{v}$,

$$
\mathfrak{R}_{v}=\frac{v_{\text {signal }}}{\phi_{\text {det }}}
$$

where $v_{\text {signal }}$ is the output of the detector (in volts) and $\phi_{\text {det }}$ is the laser flux on the detector (in watts). With the noise figure, $v_{n} / \sqrt{\Delta f}$, where $\Delta f$ is the electrical bandwidth, we can also calculate normalized detectivity $\left(D^{*}\right)$, a commonly used figure of merit for detectors. This is used to compare the sensitivity of detectors of different sizes and electrical bandwidths,

TABLE I. Measured results for Ni antennas coupled to Ni microbolometers at $10.6 \mu \mathrm{m}$.

\begin{tabular}{lccccc}
\hline \hline \multicolumn{1}{c}{ Device } & $\begin{array}{c}\text { Signal } \\
(\mathrm{mV})\end{array}$ & $\begin{array}{c}\text { Flux onto } \\
\text { detector } \\
(\mu \mathrm{W})\end{array}$ & $\begin{array}{c}\text { Noise } \\
\text { figure } \\
(\mathrm{nV} / \sqrt{\mathrm{Hz}})\end{array}$ & $\begin{array}{c}\text { Voltage } \\
\text { responsivity } \\
\mathfrak{R}_{v}(\mathrm{~V} / \mathrm{W})\end{array}$ & $\begin{array}{c}D^{*} \\
(\mathrm{~cm} \sqrt{\mathrm{Hz}} / \mathrm{W})\end{array}$ \\
\hline Without membrane & 0.3 & 30 & 6.12 & 10.1 & $5.69 \times 10^{5}$ \\
With membrane, no vacuum & 1.03 & 2.14 & 5.7 & 481 & $2.89 \times 10^{7}$ \\
Membrane, under vacuum & 3.54 & 2.14 & 5.7 & 1656 & $1.03 \times 10^{8}$ \\
\hline \hline
\end{tabular}




$$
D^{*}=\frac{\Re_{v}}{v_{n}} \sqrt{A_{\operatorname{det}} \Delta f}
$$

Here $A_{\text {det }}$ is the area of the detector. Our thermal isolation technique succeeded in increasing the responsivity and $D^{*}$ of the sensor by two orders of magnitude. Creating the membrane had a large effect on the responsivity, increasing it by a factor of 47.6; operating the membrane under vacuum further reduced thermal loss paths and increased responsivity by an additional factor of 3.44 .

\section{CONCLUSION}

By fabricating an antenna-coupled microbolometer on a membrane of $\mathrm{Si}_{3} \mathrm{~N}_{4}$, we have increased the responsivity and $D^{*}$ of the device through improved thermal isolation. The fabrication process uses conventional lithography and thin film deposition techniques and relies on the isotropic wet etching of a sacrificial $\mathrm{SiO}_{2}$ layer underneath a $400 \mathrm{~nm}$ layer of $\mathrm{Si}_{3} \mathrm{~N}_{4}$ that makes up the membrane. Comparison between an antenna-coupled microbolometer on a substrate and the same device on a $\mathrm{Si}_{3} \mathrm{~N}_{4}$ membrane showed an increase of two orders of magnitude in responsivity when the device was measured under vacuum.

Thermal isolation can be increased by reducing the thickness of the membrane, or by creating a free-standing antenna-coupled microbolometer. Another way to increase responsivity would be to investigate different materials for the antenna or the microbolometer, with consideration of such properties as the thermal conductivity and TCR of the metal, and impedance matching of the antenna to the microbolometer. The use of a ground plane is also being investigated.

${ }^{1}$ P. W. Kruse and D. D. Skatrud, Uncooled Infrared Imaging Arrays and Systems (Academic, San Diego, 1997).

${ }^{2}$ F. J. Gonzalez and G. D. Boreman, Infrared Phys. Technol. 46, 418 (2005).

${ }^{3}$ F. Wooten, Optical Properties of Solids (Academic, New York, 1972).

${ }^{4}$ F. J. Gonzalez, B. Ilic, J. Alda, and G. D. Boreman, IEEE J. Sel. Top. Quantum Electron. 11, 117 (2005). 